\title{
Uses of Information and Communication Technology among Women during Pregnancy
}

Jayaseelan $\mathbf{R}^{*}$ and Pichandy $\mathbf{C}$

Department of Mass Communication and Journalism, PSG College of Arts and Science, India

\begin{abstract}
This paper examines how pregnant women living in India use information and communication technologies (ICTs), principally internet, to access pregnancy-related information. Further the researchers considered women with the Indian family system have to take more household activities and their health system hence they may tend to prefer reading online as the best method to gather the information which they need. Demographic variables such as age, educational qualification, occupation and monthly income of the respondents detailed were considered to be independent variables for the study and using information communication technology by pregnant women before and during pregnancy was categorized as dependent variables. The data was gathered through the survey method, statistical analyses were performed to find the relationships between the independent and dependent variables. In this study, the researchers attempt to understand how the new media of technologies are being accessed, used and gratified by educated, young pregnant women on their health related queries through new media of communication.

This study is expected to throw newer lights on the growing reliance on new media technology among the first time literate pregnant women.
\end{abstract}

Keywords: E-health; Pregnant women; Health information; New media; ICT

\section{Introduction}

The rapid development of ICT (Information Communication Technology) in the past few decades has tremendously changed the life style of human beings around the world. This improves the knowledge and provides a quality life style to everyone. Today $40 \%$ of the world population use internet whereas in year $201337.9 \%$ of them have had access to it (http://www.internetlivestats.com/). This evolution in usage of internet has made people to gain more and more knowledge and makes them experts.

The development of advanced technologies in search engines like google, yahoo search, top search and social media like Facebook, twitter, blogs and IT device such as mobile phones, laptops and desktops have become store houses of information. The social media has completely transformed the way people consume information.

Pregnancy is an important phase in a woman's life although the sources of information have varied over time and between places [1]. Presently internet has become a powerful informative tool for obtaining such information and all literate women are aware of its usage. It is believed that women often turn to internet to seek information related to pregnancy. Margareta Larsson et al. [2] study finds out Swedish pregnant women often use internet for seeking information related to pregnancy. In results of the study $91 \%$ of the women had access to Internet and $84 \%$ of them used internet most frequently, most often in the early stages of their pregnancy and $55 \%$ of them always crosschecked those information that were given by the midwives with the internet. Similarly Declercq ER et al. [3] points out that internet use among pregnant women are common and frequent and this caused decline attendance at childbirth education classes. According to a mother's survey, participation in childbirth classes dropped from $70 \%$ to $56 \%$ among first-time mothers and from $19 \%$ to $9 \%$ among experienced mothers. There are many advantages in using internet. A woman user can switch over from printed books or magazines into an electronic format such as their online versions. This offers fast access and more updates compared to the printed versions. Moreover the readers are free to filter the contents according to their preferences and they tend to get an opportunity to give feedbacks or share their opinion with others on the articles in a blog or a website. If they feel they need guidance from an expert they can easily mail them or text them in a social network so that they can respond to their queries immediately.

The prime objective of the study is to understand the usage of internet among pregnant women in Tamil Nadu, India.

- To find out how women use ICT before, during and after pregnancy?

- To find out how they seek information on the internet?

- Do they rely on that information on the internet?

The conceptual frame work for the study is on the premise of the quest for seeking information and deriving satisfaction, which is best demonstrated by the studies of Kaye and Johnson and Rachelle Powell using the 'uses and gratification' paradigm. They demonstrate the use of new media that brings forth the needs that get gratified.

\section{Review of Literature}

Pam Lowe et al. [4] indicate women are encouraged to know about pregnancy in a formal method (e.g., information leaflets, antenatal classes, books). In addition, informal stories on pregnancy and birth are routinely shared between them. Traditional information cannot cover all possible outcomes, and the internet is one of the effective media to fill these gaps.

*Corresponding author: Jayaseelan $\mathrm{R}$, Department of Mass Communication and Journalism, PSG College of Arts and Science, Coimbatore, Tamil Nadu, India, Tel: +91-98-434-86661; E-mail: jayaseelan.sr@gmail.com

Received June 23, 2016; Accepted July 20, 2016; Published July 25, 2016

Citation: Jayaseelan R, Pichandy C (2016) Uses of Information and Communication Technology among Women during Pregnancy. J Mass Communicat Journalism 6 : 309. doi:10.4172/2165-7912.1000309

Copyright: (c) 2016 Jayaseelan R, et al. This is an open-access article distributed under the terms of the Creative Commons Attribution License, which permits unrestricted use, distribution, and reproduction in any medium, provided the original author and source are credited. 
Lagan BM et al. [5] assert that internet access and usage is almost universal, providing new chances and increasing challenges for health care practitioners, with pregnant women apparently turning to the new media for information during pregnancy.

Jayanthi Maniam argue that there is lots of information widely available in printed form but usually this information is general, too lengthy and complicated. One of the very easy and fast ways to access information about pregnancy is internet.

According to child birth connection survey in 2012 many women used subscription services like newsletters for delivery of pregnancy and birth information. Many women received regular information about pregnancy and birth from a content provider: $67 \%$ signed up to receive weekly emails on pre and post pregnancy.

Internet is used as medium of information among women, they access it to know what they need, and it is one of the fastest-growing informative medium in wide range. It gives information on various health-related issues, including pregnancy and childbirth [5-8].

In olden days, midwives, obstetricians, general practitioners and pediatricians had been the main information providers to women on their pregnancy, care and treatment, but there are a mounting number of articles which indicate that there may be a shift as women go often to new media for seeking health information. Larsson et al. [9] conducted a study in Sweden in which $84 \%$ of women sought pregnancy information online, the median number of searches per month were four, with some women reporting going online for pregnancy information as often as twice each day and they feel they getting adequate information which they are in need. The internet was named by pregnant women as an adequate trusted source for advice on the use of home remedies to maintain their health during pregnancy; however, due to the small $(n=27)$ nonrandom design, and geographic specificity of the study, no generalizations could be made. National Partnership for Women and Families conducted a survey in 2014 whose result was that nearly $64 \%$ of pregnant women in the survey accessed online information through smartphones in a week to clear their doubts, and $82 \%$ accessed the net using computers.

Researchers Lagan et al. [5] indicates that nearly half of the respondents reported dissatisfaction with information given by health professionals $(48.6 \%)$ and lack of time to ask health professionals questions (46.5\%) as key factors influencing them to access the Internet. Statistically, women's confidence levels significantly increased with respect to clearing their doubts about their pregnancy after Internet usage $(\mathrm{p}<0.05)$.

JoAnne Herman et al. [1] explores that discussion board is the most effective way to deliver informational social support on a comprehensive social support web site. Participants were able to take tips from Web site easily. They accessed the discussion board the most frequently, followed by changes during pregnancy by month, ask-a-nurse feature, ultrasound, stories about pregnant women, and spirituality. In an another study by Carina Sparud-Lundin et al. [10] explain about the importance of the web-based tips need for women with type 1 diabetes in relation to childbearing. This user directed study indicates specific areas of development for the provision of effective web-based support that includes facilities for reliable information, interactive support and social networking in this population.

Kate rope argues, according to the Centers for Disease Control and Prevention (CDC), 90 percent of women take medication at some point in their pregnancy and 70 percent take prescription medication.
And yet women facing these decisions are often given conflicting information on medication safety from their primary care providers and the Internet. Katri Hameen-Anttila concluded in their study a large proportion of pregnant women report the need for information about medicines during pregnancy, $73 \%$ rely on healthcare professionals and $60 \%$ rely on internet it is a widely used information source across the countries in this study.

Tares comments on how women need to connect and bond with one another during pregnancy, and to rely on other women for support. DIPEx.org is an example of a website developed in the UK where women can listen to a number of different audio-visual interviews of women talking about their experience of antenatal screening, as well as accessing information on treatment choices and where to find support.

Capitulo's qualitative study using ethnography to describe and interpret the culture of an online perinatal loss group, found the essence of the culture was 'shared metamorphosis'. The culture of online support can link individuals who are geographically distant but share common issues. The internet linked women together who otherwise would not have met. Participants shared virtual identities, created a community and by joining the perinatal loss listserv ensured that they would never be alone.

Rillstone in his exploratory descriptive study noted how some women who had a previous pregnancy with a fetal abnornality benefited from accessing the internet for support when faced with a subsequent pregnancy. Pemberton and Goldblatt give an example of a case study where a pregnant woman carrying a baby with a congenital abnormality sourced information from the internet.

Devan Mcguinness found out in her study that pregnant women admit to getting lots of information from the internet and say that it is very reliable and useful. They also cross check few things once in a while, but the information is so valuable.

Internet is used as a medium of information among women, they access it to know what they need, and it is one of the fastest-growing informative medium covering a wide range of audience. It gives information on various health-related issues, including pregnancy and child development stage by stage [7,11-15].

Margareta Larsson [2], points out in the study that $91 \%$ of the female accessed internet in which $84 \%$ used it to collect and to retrieve information on a most interested search was on fetal development and child development.

Jay M Bernhardt [7] The mothers in our study reported going online to learn more about the stages of fetal and child development, especially for their first child. The information that these women found most useful were messages that were matched, or tailored, to their specific stage of pregnancy or the developmental stage of their child.

Yet another study by Ernst and Schmidt stated how internet obscures people on giving information about herbal medicine. This was a good example of how advice given via the new media can be unclear, incorrect, lacking in scientific rationale and does not always provide warning information; this may put women and their fetuses at risk.

Women from various parts of the country have the same tendency proving that internet is the primary and reliable source to find information related to pregnancy. A study which was held in Sweden indicates approximately three fourths of the Swedish survey's women respondents (exact figure not reported) rated that pregnancy-related information they found online to be moderately or highly reliable [8]. 
In an yet another study conducted by Margareta Larsson [8], it is concluded that most of the participants considered that the information on the internet is reliable, and the two most important criteria for judging the trustworthiness of web-based information were to find out if the facts were consistent with information from other sources and if the references were provided for them.

Many women rely so much on the information from ICT (Information Communication Technology) as found out in the study of Gabriela Cormick et al. [16]. According to it most of the women who were interviewed have access to ICT and were most interested in receiving text messages and calls with educational information regarding maternity and infant health. Pregnant ladies in Argentina might have benefited via such an ICT program.

\section{Research Methodology}

This investigation on the 'New Media use for health and reproduction related issues among the new literate and young mothers' entails understanding the choice of pregnant women using new media as a source of information related to pregnancy. Hence, the researcher has to identify a cross section of pregnant women in Tamil Nadu and know from them where and how they get information related to pregnancy. It also becomes important to investigate who among them prefer which type of medium for gathering information.

In this process the researcher has to focus on identifying pregnant women in various hospitals and scan centers to collect data so as to have a representative sample.

When the researchers embarked on this study, women who were pregnant were more enthusiastic in knowing their health and infant development. Hence the focus on this study is to know how they use information communication technology is being used to gather information related on pregnancy.

Further the researchers considered women with the Indian family system have to take more household activities and their health system hence they may tend to prefer reading online as the best method to gather the information which they need.

Demographic variables such as age, educational qualification, occupation and monthly income of the respondents detailed were considered to be independent variables for the study and using information communication technology by pregnant women during pregnancy and before pregnancy which was categorized as dependent variables.

On the data gathered through the survey method, statistical analyses were performed to find the relationships between the independent and dependent variables.

\section{Research Questions}

As detailed earlier, the present study requires measuring the usage of information communication technology (ICT) among the pregnant women during their pregnancy period for collecting information related to their health and infant development. Hence, the following research questions are mooted in this study so as to understand how the pregnant women use ICT for seeking information and accordingly research questions are generated below.

1) Is there any perceptional difference among pregnant women in general on using ICT tools before and during pregnancy?
2) Whether pregnant women differ in their perception in preferring online information?

3)Is there any difference in perception in preferring online information among pregnant women according to their age, education and occupation?

In order to answer the above research questions and to understand those intricacies the researcher developed an attitude scale so as to measure those factors which are taken from the study (Table 1).

The researcher collected a total sample from 421 respondents. After careful scrutiny it was found that some of the respondents did not answer some of the questions and some of the items were incomplete. After removing those incomplete samples, the final tally of respondents included in the study is 334 [17].

Table 2, results of ' $\mathrm{T}$ ' test reveals the following 9 statements. Statement 1: The results of ' $T$ ' test show no significant difference between the employed and unemployed women of the respondents and reading newsletter. Statement 2: The results of the ' $\mathrm{T}$ ' test shows there is significant difference in getting adequate information and employed women have the higher significant value $m=3.84$. Statement 3: The results of the ' $\mathrm{T}$ ' test reveal that there is significant difference and employed women have higher inclination towards the statement on clearing their doubts $m=3.40$. Statement 4 : The results of ' $T$ ' test show no significant difference between the employed and unemployed women of the respondents and following tips from the internet. Statement 5: The results of ' $\mathrm{T}$ ' test show there is no significant difference between the employed and unemployed women of the respondents and taking medication with the help of internet during pregnancy. Statement 6: The results of ' $\mathrm{T}$ ' test show there is no significant difference on sharing their opinion with other pregnant women during pregnancy. Statement 7: The results of ' $T$ ' test show there is no significant difference on shared useful information in the website by others. Statement 8: The results of the ' $T$ ' test reveal that there is significant difference and employed women have higher inclination towards tracking child's development $\mathrm{m}=3.51$. Statement 9: The results of the ' $\mathrm{T}$ ' test reveal that there is significant difference and employed women have higher inclination towards the statement relying on internet information $\mathrm{m}=3.90$.

Table 3 and 3A, results of 'ANOVA' test reveal the following 9 statements. Statement 1: The table of one way Analysis of Variance reveals the age of the respondents in terms of reading newsletters regularly is not significant. Statement 2: The table of one way Analysis of Variance reveals the age of the respondents in terms of getting adequate information is not significant. Statement 3: The table of one way Analysis of Variance shows that there is a significant difference in clearing their doubts through new media after consulting their doctor. The table of means reveals that respondents of the age group 31 years and above have a higher mean value of $m=3.65$. Statement 4 : The table of one way Analysis of Variance shows that there is a significant

\begin{tabular}{|l|l|c|c|c|}
\hline Pair 1 & $\begin{array}{l}\text { How long do you use computer to access } \\
\text { Internet }\end{array}$ & 1.157 & df & Sig. (2-tailed) \\
\hline
\end{tabular}

Table 1: Paired samples test.

\begin{tabular}{|l|l|l|l|l|}
\hline Pair 1 & $\begin{array}{l}\text { Mean } \\
\text { How long do you use computer to access Internet }\end{array}$ & 1.8503 & 334 & 1.05483 \\
\hline $\begin{array}{l}\text { (Before) } \\
\begin{array}{l}\text { How long do you use computer to access Internet } \\
\text { (During) }\end{array}\end{array}$ & 1.7844 & 334 & 0.86729 \\
\hline
\end{tabular}

Table 1A: Paired samples statistics - internet usage before and during. 
Citation: Jayaseelan R, Pichandy C (2016) Uses of Information and Communication Technology among Women during Pregnancy. J Mass Communicat Journalism 6: 309. doi:10.4172/2165-7912.1000309

Page 4 of 7

\begin{tabular}{|c|c|c|c|c|}
\hline S.NO & & $\mathbf{T}$ & DF & SIG \\
\hline 1 & Do you read the news letters regularly that comes to your e-mail & 4.477 & 332 & 0.326 \\
\hline 2 & Do you get adequate information which you expect to know & 6.288 & 332 & 0.006 \\
\hline 3 & Do you go back to those websites to clear your doubts & 1.273 & 332 & 0.000 \\
\hline 4 & Do you follow tips from the websites & 2.365 & 332 & 0.453 \\
\hline 5 & Do you take medication with the help of websites & -0.497 & 332 & 0.256 \\
\hline 6 & Do you share your experiences and opinion with others in the websites & 6.801 & 332 & 0.129 \\
\hline 7 & Do you find the shared information of the other members useful & 6.094 & 332 & 0.816 \\
\hline 8 & Do you visit the websites every week to track your child's development & 2.894 & 332 & 0.000 \\
\hline 9 & Do you rely on the information that you get on the internet & 5.463 & 332 & 0.006 \\
\hline
\end{tabular}

Table 2: Table of ' $T$ ' Test for nine statements.

\begin{tabular}{|c|c|c|c|}
\hline & Occupation & $\mathbf{N}$ & Mean \\
\hline \multirow[b]{2}{*}{ 1. Do you read the news letters regularly related to pregnancy which comes to you through e-mail } & Employed & 184 & 3.6196 \\
\hline & Un Employed & 150 & 3.0000 \\
\hline \multirow{2}{*}{ 2. Do you get adequate information which you expect to know } & Employed & 184 & 3.8424 \\
\hline & Un Employed & 150 & 3.0867 \\
\hline \multirow{2}{*}{ 3. Do you go back to those websites to clear your doubts } & Employed & 184 & 3.4076 \\
\hline & Un Employed & 150 & 3.2200 \\
\hline \multirow{2}{*}{ 4. Do you follow tips from the websites } & Employed & 184 & 3.3641 \\
\hline & Un Employed & 150 & 3.0267 \\
\hline \multirow{2}{*}{ 5. Do you take medication with the information from the websites } & Employed & 184 & 1.1467 \\
\hline & Un Employed & 150 & 1.1733 \\
\hline \multirow{2}{*}{ 6. Do you share your experiences and opinion with other members on the websites } & Employed & 184 & 3.2772 \\
\hline & Un Employed & 150 & 2.3667 \\
\hline \multirow{2}{*}{ 7. Do you find the shared information of the other members useful } & Employed & 184 & 3.4130 \\
\hline & Un Employed & 150 & 2.7200 \\
\hline \multirow{2}{*}{ 8. Do you visit the websites every week to track your child's development } & Employed & 184 & 3.5163 \\
\hline & Un Employed & 150 & 3.1400 \\
\hline \multirow{2}{*}{ 9. Do you rely on the information that you get on the internet } & Employed & 184 & 3.9022 \\
\hline & Un Employed & 150 & 3.0800 \\
\hline
\end{tabular}

Table 2A: Table of nine statements in te

\begin{tabular}{|c|c|c|c|c|}
\hline \multirow{5}{*}{ 1. Do you read the news letters regularly that comes to your e-mail } & Age & $\mathbf{N}$ & Mean & Std. Dvt \\
\hline & 21 to 25 & 136 & 3.2059 & 1.14903 \\
\hline & 26 to 30 & 114 & 3.3246 & 1.17115 \\
\hline & 31 and above & 84 & 3.5833 & 1.61475 \\
\hline & Total & 334 & 3.3413 & 1.29342 \\
\hline \multirow{4}{*}{ 2. Do you get adequate information which you expect to know } & 21 to 25 & 136 & 3.3456 & 1.18870 \\
\hline & 26 to 30 & 114 & 3.5789 & .80809 \\
\hline & 31 and above & 84 & 3.6548 & 1.44367 \\
\hline & Total & 136 & 3.3456 & 1.18870 \\
\hline \multirow{4}{*}{ 3. Do you go back to those websites to clear your doubts } & 21 to 25 & 136 & 3.0662 & 1.42570 \\
\hline & 26 to 30 & 114 & 3.4474 & .99638 \\
\hline & 31 and above & 84 & 3.5714 & 1.53894 \\
\hline & Total & 334 & 3.3234 & 1.34128 \\
\hline \multirow{4}{*}{ 4. Do you follow tips from the websites } & 21 to 25 & 136 & 3.0221 & 1.18301 \\
\hline & 26 to 30 & 114 & 3.0965 & 1.22633 \\
\hline & 31 and above & 84 & 3.6786 & 1.49021 \\
\hline & Total & 334 & 3.2126 & 1.30592 \\
\hline \multirow[t]{4}{*}{ 5. Do you take medication with the help of websites } & 21 to 25 & 136 & 1.2353 & .59920 \\
\hline & 26 to 30 & 114 & 1.1491 & .46530 \\
\hline & 31 and above & 84 & 1.0476 & .21424 \\
\hline & Total & 334 & 1.1587 & .48580 \\
\hline \multirow{4}{*}{$\begin{array}{l}\text { 6. Do you share your experiences and opinion with others in the } \\
\text { websites }\end{array}$} & 21 to 25 & 136 & 2.7500 & 1.19722 \\
\hline & 26 to 30 & 114 & 2.7895 & 1.06824 \\
\hline & 31 and above & 84 & 3.1667 & 1.65619 \\
\hline & Total & 334 & 2.8683 & 1.29703 \\
\hline \multirow{4}{*}{ 7. Do you find the shared information of the other members useful } & 21 to 25 & 136 & 2.9706 & 1.02517 \\
\hline & 26 to 30 & 114 & 3.1228 & .71816 \\
\hline & 31 and above & 84 & 3.2857 & 1.50958 \\
\hline & Total & 334 & 3.1018 & 1.08849 \\
\hline \multirow{4}{*}{$\begin{array}{l}\text { 8. Do you visit the websites every week to track your child's } \\
\text { development }\end{array}$} & 21 to 25 & 136 & 3.2574 & .94278 \\
\hline & 26 to 30 & 114 & 3.3158 & 1.13913 \\
\hline & 31 and above & 84 & 3.5357 & 1.57117 \\
\hline & Total & 334 & 3.3473 & 1.19523 \\
\hline \multirow[t]{4}{*}{ 9. Do you rely on the information that you get on the internet } & 21 to 25 & 136 & 3.5074 & 1.39309 \\
\hline & 26 to 30 & 114 & 3.5965 & 1.30159 \\
\hline & 31 and above & 84 & 3.4881 & 1.63909 \\
\hline & Total & 334 & 3.5329 & 1.42599 \\
\hline
\end{tabular}

Table 3: One way analysis for 9 statements in terms of age. 
Citation: Jayaseelan R, Pichandy C (2016) Uses of Information and Communication Technology among Women during Pregnancy. J Mass Communicat Journalism 6: 309. doi:10.4172/2165-7912.1000309

Page 5 of 7

1.Do you read the news letters regularly that comes to your e-mail

2. Do you get adequate information which you expect to know

3. Do you go back to those websites to clear your doubts

4. Do you follow tips from the websites

5. Do you take medication with the help of websites

6. Do you share your experiences and opinion with others in the websites

7. Do you find the shared information of the other members useful

8. Do you visit the websites every week to track your child's development

9. Do you rely on the information that you get on the internet

Table 3A: Table of mean for 9 statements in terms of age.

\begin{tabular}{|c|c|c|c|c|}
\hline \multirow{5}{*}{ 1. Do you read the news letters regularly that comes to your e-mail } & & $\mathbf{N}$ & Mean & Std. Dvt \\
\hline & UG & 71 & 2.8310 & 1.46371 \\
\hline & PG & 181 & 3.6961 & 1.18857 \\
\hline & Other & 82 & 3.0000 & 1.12217 \\
\hline & Total & 334 & 3.3413 & 1.29342 \\
\hline \multirow{4}{*}{ 2. Do you get adequate information which you expect to know } & UG & 71 & 2.7887 & 1.45323 \\
\hline & PG & 181 & 3.8674 & 0.95690 \\
\hline & Other & 82 & 3.3171 & 0.91460 \\
\hline & Total & 334 & 3.5030 & 1.15405 \\
\hline \multirow{4}{*}{ 3. Do you go back to those websites to clear your doubts } & UG & 71 & 2.9296 & 1.52432 \\
\hline & PG & 181 & 3.6519 & 1.25404 \\
\hline & Other & 82 & 2.9390 & 1.16902 \\
\hline & Total & 334 & 3.3234 & 1.34128 \\
\hline \multirow{4}{*}{ 4. Do you follow tips from the websites } & UG & 71 & 2.5070 & 1.40279 \\
\hline & $P G$ & 181 & 3.5580 & 1.16104 \\
\hline & Other & 82 & 3.0610 & 1.26049 \\
\hline & Total & 334 & 3.2126 & 1.30592 \\
\hline \multirow{4}{*}{ 5. Do you take medication with the help of websites } & UG & 71 & 1.2254 & 0.72105 \\
\hline & $P G$ & 181 & 1.0718 & 0.25891 \\
\hline & Other & 82 & 1.2927 & 0.57709 \\
\hline & Total & 334 & 1.1587 & 0.48580 \\
\hline \multirow{4}{*}{$\begin{array}{l}\text { 6. Do you share your experiences and opinion with others in the } \\
\text { websites }\end{array}$} & UG & 71 & 2.0704 & 1.09966 \\
\hline & PG & 181 & 3.0829 & 1.36577 \\
\hline & Other & 82 & 3.0854 & 1.00862 \\
\hline & Total & 334 & 2.8683 & 1.29703 \\
\hline \multirow{4}{*}{ 7. Do you find the shared information of the other members useful } & UG & 71 & 2.6901 & 1.33728 \\
\hline & $P G$ & 181 & 3.2928 & 1.08904 \\
\hline & Other & 82 & 3.0366 & 0.67486 \\
\hline & Total & 334 & 3.1018 & 1.08849 \\
\hline \multirow{4}{*}{$\begin{array}{l}\text { 8. Do you visit the websites every week to track your child's } \\
\text { development }\end{array}$} & UG & 71 & 2.9014 & 1.31100 \\
\hline & $P G$ & 181 & 3.5414 & 1.15696 \\
\hline & Other & 82 & 3.3049 & 1.07369 \\
\hline & Total & 334 & 3.3473 & 1.19523 \\
\hline \multirow{4}{*}{ 9. Do you rely on the information that you get on the internet } & UG & 71 & 2.5352 & 1.64604 \\
\hline & PG & 181 & 3.8840 & 1.13667 \\
\hline & Other & 82 & 3.6220 & 1.41107 \\
\hline & Total & 334 & 3.5329 & 1.42599 \\
\hline
\end{tabular}

Table 4: One way analysis for 9 statements in terms of education.

difference following tips from websites. The table of means shows that respondents of the age group 31 years and above have a higher mean value of $m=3.67$. Statement 5: The table of one way Analysis of Variance shows that there is a significant difference taking medication with the support of websites. The respondents of the age group 21 to 25 have a higher mean value of $m=1.23$. Statement 6 : The table of one way Analysis of Variance shows that there is a significant difference in terms of sharing opinions. The respondents of the age group 31 years and above have a higher mean value of $m=3.16$. Statement 7: The table of one way Analysis of Variance reveals the age of the respondents in terms of finding information shared by others in the website is useful is not significant. Statement 8: The table of one way Analysis of Variance reveals the age of the respondents in terms of tracking the infant development with help of internet is not significant. Statement 9: The table of one way Analysis of Variance reveals the age of the respondents in terms of relying on the information that appears in internet is not significant.

Table 4 and 4A, results of 'ANOVA' test reveal the following 9 statements. Statement 1: The table of one way Analysis of Variance shows that there is a significant difference in reading newsletter. 
1.Do you read the news letters regularly that comes to your e-mail

2. Do you get adequate information which you expect to know

3. Do you go back to those websites to clear your doubts

4. Do you follow tips from the websites

5. Do you take medication with the help of websites

6. Do you share your experiences and opinion with others in the websites

7. Do you find the shared information of the other members useful

8. Do you visit the websites every week to track your child's development

9. Do you rely on the information that you get on the internet

Table 4A: Table of mean for 9 statements in terms of education

\begin{tabular}{|c|c|}
\hline How long do you use the computer to access Internet & During \\
\hline Before & $0.427^{* *}$ \\
\hline
\end{tabular}

** Correlation is significant at the 0.01 level (2-tailed)

Table 5: Table for correlation on usage of internet before and during pregnancy.

Respondents who have finished post-graduation have a higher mean value of $m=3.96$. Statement 2: The table of one way Analysis of Variance reveals there is a significant difference. The table of means shows postgraduation degree holders with a mean value of 3.86 is more inclined towards getting adequate information from internet. Statement 3: The results of the One way Analysis of Variance show that there is a significant value in clearing their doubts according to educational qualification. Women who are post-graduates have the highest mean value of $m=3.65$. Statement 4 : The results of the one way Analysis of Variance show that there is a significant value in following tips from websites. The table of means shows that respondents who have finished post-graduation have a higher mean value of $m=3.55$. Statement 5 : The results of the one way Analysis of Variance show that the educational qualification of the respondents in terms of taking medication with the help of internet is significant. The table of mean explains that 'others' have the highest mean value of $\mathrm{m}=1.29$. Statement 6 : The table of one way Analysis of Variance shows that there is a significant difference in sharing experiences and opinion on the websites. Respondents in others category and post-graduation have slight difference with a mean value of $\mathrm{m}=3.085$ and 3.082 in sharing opinion with others in internet. Statement 7: The results of one way Analysis of Variance indicate that the educational qualification of the respondents in terms of finding useful information is significant. The table of mean details that the respondents with post-graduation degree having a mean value of $m=3.29$. Statement 8 : From the results of the table of one way Analysis of Variance, it may be understood that the education of the respondents in terms of tracking the developments on infants is significant. Respondents who are post-graduates have a higher mean value of $m=3.54$. Statement 9: The table of one way Analysis of Variance reveals that the educational qualification of the respondents with reference to the statement "Do you rely on the information that you get on the internet" is significant. The table of means shows respondents with post-graduation have higher mean value of $\mathrm{m}=3.88$.

Table 5 results of co-relation reveal that there is significant level of positive relationship between the usage of internet before and during pregnancy and that of the medium per se. It is interesting to note that women use the new medium equally before and during pregnancy with their high co-relation levels.

\section{Discussion and Conclusion}

With an intense penetration of the digital media, it can be perceived that there has been a slight transition from the traditional method of information gathering to the advanced online information sourcing among the Indian pregnant women.

As working women they spend most of their time in the office in front of computer especially in internet. During pregnancy the level of usage becomes slightly less comparing the times before pregnancy which may be due to various reasons. Mercola [18] says women who are pregnant should switch off their mobile phones and laptops when they are not using it.

Women use internet as one of the important media of information. They often read the newsletters that come through e-mail which can provide them with adequate information which they need. It is observed that the employed women are not willing to take any medication with help of internet. The unemployed women are found to share their opinions with the others. On the whole employed women have more influence on new media compared to unemployed. Lagan B et al. [17] indicate working pregnant women, reportedly turning to new media for information during pregnancy, will have a better understanding of their health and infant development.

In terms of age group the respondents with the higher age group have more influence in using the new media and they are more influenced on most of the statements. In the same way women in the higher age group do not take medication with the help of internet but the women in the age group 21 to 25 years have some influence on taking medication with the help of internet. Some women have more belief that the information on the new media is very much true and they rely on it [18-20]. A study which was held in Sweden indicates, approximately three fourths of the Swedish survey's women respondents (exact figure not reported) rated that pregnancy-related information they found online to be moderately or highly reliable [21-25].

When it comes to education the post-graduates and women who have studied above post-graduation have more influence on all the statements compared to the undergraduates [25-28]. This indicates that those who are more educated use more internet for knowledge gain. Internet is used as medium of information among women, they access it to know what they need, and it is one of the fastest-growing informative media in a wide range. It provides with information on various health-related issues, including pregnancy and childbirth [28-34].

This research incurred that women are more conversant about the technology and its usage. With different types of tests, the researcher comes out with a conclusion that there is slight variation among the pregnant women in usage of ICT before and during pregnancy. From the results of the study it is predicted that working women use new media in a positive way to find information and the rate of usage is higher while compared to the unemployed women. It is quite interesting to note that considered age-wise, aged women use internet more often compared to the other age groups [35-40]. 
Citation: Jayaseelan R, Pichandy C (2016) Uses of Information and Communication Technology among Women during Pregnancy. J Mass Communicat Journalism 6: 309. doi:10.4172/2165-7912.1000309

Women who are educated post-graduation and above postgraduation use the internet most frequently when compared to the undergraduates, this indicates that women who are educated more, use internet more frequently. Women belonging to middle class and higher class use internet more, as an informative tool, comparing to lower level women [41-43].

\section{References}

1. Herman J, Mock K, Blackwell D, Hulsey $T$ (2005) Use of a pregnancy support web site by low-income African American women. JOGNN 34: 713-720.

2. Johanssona M, Rubertsson C, Radestad I, Hildingssond I (2010) The Internet: one important source for pregnancy and childbirth information among prospective fathers. Journal of Men's Health 7: 249-258.

3. Declercq ER, Sakala C, Corry MP, Applebaum S, Risher P (2002) Report of the first national U.S. survey of women's childbearing experiences. New York: Maternity Center Association.

4. Lowe P, Powell J, Griffiths F, Thorogood M, Locock L (2009) Making it all normal: the role of the internet in problematic pregnancy. Qual Health Res 19: 1476-1484.

5. Lagan BM, Sinclair M, Kernohan WG (2010) Internet use in pregnancy informs women's decision making: a web-based survey. Birth 37: 106-115.

6. Bowena D, Meischkea H, Busha N, Wooldridgea J, Robbinsa R, et al. (2003) Predictors of women's internet access and internet health seeking. Health Care for Women International 24: 940-951.

7. Bernhardt JM, Felter EM (2004) Online pediatric information seeking among mothers of young children: results from a qualitative study using focus groups. J Med Internet Res 6: 1-2.

8. Larsson M (2009) A descriptive study of the use of the Internet by women seeking pregnancy-related information. Midwifery 25: 14-20.

9. Sparud-Lundin C, Ranerup A, Berg M (2011) Internet use, needs and expectations ofweb-based information and communication in childbearing women with type 1 diabetes. Medical Informatics and Decision Making 11: 49.

10. Adler CL, Zarchin YR (2002) The virtual focus group: using the Internet to reach pregnant women on home bed rest. J Obstet Gynecol Neonatal Nurs 31: 418-427.

11. http://transform.childbirthconnection.org/wp-content/uploads/2013/05/LTMIIIDB-infosources.pdf

12. Romano AM (2007) A changing landscape: implications of pregnant women's internet use for childbirth educators. J Perinat Educ 16: 18-24

13. Kersting A (2011) A randomized controlled trial. archives of women's mental health.

14. Ofosu A (2012) Mobile devices-the essential medical equipment for the future. Citeseerx. pp. 1-7.

15. Chiba A, Lwina MO, Anga J, Lina H, Fiana (2008) Midwives and mobiles: using ICTs to improve healthcare in Aceh Besar, Indonesia. Asian Journal of Communication 18: 348-364.

16. Cormick G, Kim NA, Rodgers A, Gibbons L, Buekens PM, et al. (2012) Interes of pregnant women in the use of SMS (short message service) text messages for the improvement of perinatal and postnatal care. Reprod Health 9: 9-12.

17. Lagan B, Sinclair M, Kernohan WG (2006) Pregnant women's use of the internet:a review of published and unpublished evidence. Evidence Based Midwifery 4: 17-23.

18. Mercola (2012) Should pregnant women avoid using cell phones?

19. Lagan BM, Sinclair M, Kernohan WG (2011) A web-based survey of midwives perceptions of women using the Internet in pregnancy: a global phenomenon. Midwifery 27: 273-281.

20. Collado CC (2005) Women's access to ICTs in the information society. In Media and Gender: A Scholarly agenda for the Global Alliance on Media and Gender. pp: 60-68.

21. Connection C (2012) How do U.S. women use the internet and other sources of pregnancy information?

22. Crocco AG, Villasis-Keever M, Jadad AR (2002) Analysis of cases of harm associated with use of health information on the internet. JAMA 287: 2869-2871.
23. Rodger AED, Skuse AA, Wilmore BM, Humphreys BS, Dalton CDJ, et al. (2013) Pregnant women's use of information and communications technologies to access pregnancy-related health information in South Australia. Aust J Prim Health 19: 308-312.

24. Maitra A (2007) Safe Motherhood and ICT Tools in BCC.

25. WHO (2013) eHealth and innovation in women's and children's health: A baseline review. WHO Global Observatory for eHealth.

26. Eimi $L$ (2013) Prenatal googling: online information seeking by israeli women during pregnancy. International Review of Social Research 3: 69-87.

27. Lean G (2014) Warning: Using a mobile phone while pregnant can seriously damage your baby. Independent

28. Thomson H (2012) Pregnant women need not worry about cellphone use New Scientist.

29. ITU (2013) ICT for improving information and accountability for women's and children's health.Commission on Information and Accountability for Women's and Children's Health.

30. Mania J, Ken CC, Chenapiah K (2009) Mobile phone based pregnancy support system.

31. Huberty J, Dinkel D, Beets MW, Coleman J (2012) Describing the use of the internet for health, physical activity, and nutrition information in pregnant women. Matern Child Health J 17: 1363-1372.

32. Kavlak O, Atan SU, Gulec D, Ozturk R, Atay N (2012) Pregnant women's use of the internet in relation to their pregnancy in Izmir, Turkey. Inform Health Soc Care 37: 253-263.

33. http://www.naturalnews.com/035528_cell_phones_laptops_pregnant_women. $\mathrm{html}$

34. Boulos MN, Wheeler S, Tavares C, Jones R (2011) How smartphones are changing the face of mobile and participatory healthcare: an overview, with example from eCAALYX. Biomed Eng Online 10: 24.

35. Merhi ZO (2012) Challenging cell phone impact on reproduction: a review. J Assist Reprod Genet 29: 293-297.

36. Miller T (2005) Making sense of motherhood: a narrative approach. Cambridge University Press.

37. Noordam AC, Kuepper BM, Stekelenburg J, Milen A (2011) Improvement of maternal health services through the use of mobile phones. Trop Med Int Health 16: 622-626.

38. Office for National Statistics (2013) Internet Access - Households and Individuals, 2013. Office for National Statistics.

39. Peters SL, Lind JN, Humphrey JR, Friedman JM, Honein MA, et al. (2013) Safe lists for medications in pregnancy: inadequate evidence base and inconsistent guidance from Web-based information, 2011. Pharmacoepidemiol Drug Saf 22: $324-328$

40. Powell R (2005) Women's Use of The Internet. Central Missouri State University.

41. Svoronos T, Mjungu D, Dhadialla P (2010) Automated Quality Improvement To Strengthen Community-Based. SHOPS mHealth eConference, Maryland.

42. Oyeyemi SO, Wynn R (2014) Giving cell phones to pregnant women and improving services may increase primary health facility utilization: a casecontrol study of a Nigerian project. Reprod Health 11: 8-12.

43. Zero Mothers Die Consortium (2014) Saving the lives of pregnant women and children using ICTs and mobile health. Zero Mothers Die Consortium. 